\title{
Conditional Cash Transfer and The Poor in Indonesia
}

\author{
Robbie Peters \\ Department of Antropology, School of \\ Social and Political Sciences \\ The University of Sydney \\ line 4: Sydne, Australia \\ robbie.peters@sydney.edu.au
}

\begin{abstract}
This paper explores the popular poverty alleviation instrument of conditional cash transfers to the poor in the global south. Through a focus on one such program in Indonesia and those $I$ term its user, non-user and provider poor people, I highlight how cash transfers create a hierarchy of poor due to synoptic views of poverty capable only of capturing its objectively visible and quantifiable aspects. I focus on those who are anterior to the visible: those who in this study make up half of all poor people in the large Indonesian city of Surabaya.
\end{abstract}

\section{Keywords—conditional cash transfer, poverty, Indonesia}

\section{INTRODUCTION}

Indonesia's "Hopeful Families" conditional cash transfer program became permanent and nationwide in 2016 after being piloted in various forms over the previous ten years. Modelled on those in other middle-income countries and based on financial and technical advice over the decade from institutions like the World Bank, the program relies on refined data gathering methods that identify the household dynamics of almost half the Indonesian population, or almost twenty-five million households. The largest household database of its kind in the world, it more accurately identifies those families below the Indonesian poverty line, excluding those above it.

\section{CASH Transfers}

Every three months, each of these identified poor families receives a base cash instalment of USD \$13, followed by instalments of $\$ 30$ for a neo-natal child, $\$ 12$ for a primary school child, $\$ 20$ for a junior high school child and $\$ 25$ for a senior high school child and cannot exceed a total of $\$ 100$ per family (In equivalent terms per head, one would get on third of the poverty line level income of $\$ 27$ per month, or one sixth of the minimum wage of $\$ 160$ per month, which in Australia would amount to about $\$ 100$ in relative terms to the minimum wage).

The money is transferred to a bank account set up under the program. A portion of it is to be spent to buy monthly parcels of government subsidised rice, sugar and vegetable oil at recently established depositories called "e-stores". The bank account and the store decrease leakage of these products to the better off, appropriation by family members and corruption by handlers, reducing costs to government and to the poor and ensuring that the program runs according to its "evidence based" calculations.

The above amounts of money are based on the educational and nutritional needs of a child at each given age range and are considered adequate to get them out of poverty in a specified period of time. The social affairs minister who launched the new program in Surabaya in February 2017 promised that in contrast with the imprecision of previous programs, this one will achieve precision across the welfare chain by delivering cash and correctly priced foodstuffs in the right amounts and on time to the right people for the right period.

Correctly calibrated to the needs of the poor person, this cash and food would, she attested, lead them out of poverty in five years. Based on rational sociotechnical calculations, the new and precise welfare should lead a person away from the abstract suffering subject who lives below the poverty line and towards the equally abstract sustainable subject who lives above that line.

A new stratum of salaried field officers, or buddies, socialise the program in the city's poor neighborhoods and ensure that recipients send their children to school and health clinics. The cash transfers are stopped if the parent does not do what they are told to do under the program. If they do what they are told, they should become un-poor within the specified period and experience what is called a "natural exit" from the program. In addition to socialising the program and monitoring adherence, the buddies coach the poor in how to live sustainable livelihoods that are resistant to economic shocks and likely to produce a nonpoor next generation.

This model of welfare, however, is unsuited to those James Ferguson terms "those hard-to-categorise urban improvisers" of the informal economy who are best served by a policy of unconditional cash transfers that rely on their "own ability to solve their own problems". Unconditional welfare relies on what Pat O'Malley $(2015,23)$ calls “a volitional rationality in which security and freedom are founded in techniques of individual foresight and uncertainty" [1]. Under the logic of Indonesia's conditional cash transfer program by contrast, the flexible and multiple income earning strategies of its urban poor point not to their own successful volitional strategies, but to the "social 
insecurity" and "social risks" that that make them poor and that new social assistance must attenuate [2].

Aimed at attenuating social risk and insecurity, Indonesia's cash transfer program relies on what O'Malley calls "a sociotechnical, modernist rationality in which society and economy are to be managed efficiently through scientific knowledge of entities that operate according to quasi-natural laws" [1]. For the hard to categorise person of Indonesia's informal economy, this means that they must be turned from an improviser who takes risks and embarks on an economic future of multiple possibilities into a complier who remains conservative and committed to a rationally predetermined course.

Surabaya's poor have typically juggled multiple income earning activities and living places, enabling them to change jobs or locations depending on opportunities. Research shows that Surabaya's poor preferred the flexibility of juggling several low-paid jobs as scrap pickers, motorbike taxi drivers and the like over hard-toget, low-paid and irregular contract work as janitors, factory hands, truck drivers or sales assistants. Such lowpaid waged work was unattractive to the poor because it denied them the spontaneity they needed to maintain their other income earning activities. However, as I will argue, the old flexibility relied on rights to the city that todays poor no longer possess, leaving them almost totally dependent on subjecting themselves to what I call synoptic social assistance in which the state determines one's eligibility or otherwise based on objectively calculable parameters.

The typical sustainable un-poor person is a mother living in a specified location on an income above the poverty line and with children above minimum weight ranges and school attendance above eighty-five per cent. Such a person typifies what critics of conditional cash transfer programs call a normative ideal of gender and household that ignores poor women who live away from their families, poor men in general and poor people without the official documentation to verify where they live. With such a narrowly defined object of welfare, Indonesia's cash transfer program is informed by normative evaluations that bring around half of them into objective existence and sends the other half into objective non-existence.

\section{CONCLUSION}

Objective social assistance is myopic. The huge database used to identify the poor fails to identify those who lack the government verified legal documents attesting their place of birth and domicile needed to make them legible. The database also only captures those who were poor several years earlier when the data was gathered, missing those who have since become poor and missing those who are poor but not registered as living where they do. In Indonesia, where almost a quarter of the population hovers above the poverty line, determining who is poor at any one time is impossible given the number of people moving into and out of poverty each day. Although couched in a language of precision that purports to make poor people legible and therefore eligible for social assistance, objective data can also make many poor people illegible and therefore ineligible.

\section{REFERENCES}

[1] O'Malley, P.,'Uncertainty Makes Us Free: Insurance and Liberal Rationality," In Limor Samimian-Darash, Paul Rabinow (Eds.), "Modes of Uncertainty: Anthropological Cases," Chicago, United States: University of Chicago Press, 2014, pp. 13-28.

[2] Lentzos, Filippa and Rose, Nikolas, "Governing Insecurity: Contingency Planning, Protection, Resilience", Economy and Society, 38 (2) (20 May 2009), pp. 230-254. 